\title{
ESTRESSE INFANTIL E O CONTEÚDO PROGRAMÁTICO DA TELEVISÃO: um desafio para o desenvolvimento cognitivo e emocional
}

\section{CHILDHOOD STRESS AND COURSE OUTLINE OF TELEVISION: a challenge for the cognate and emotional development}

\author{
Cecília Freitas Martins (UEMS) \\ Djalma Querino de Carvalho (UEMS-UFSCar)
}

\begin{abstract}
Resumo: Ao perceber, tanto em estudos quanto em práticas realizadas, como a criança está vulnerável às condições ambientais, sociais e culturais, pois absorve com alguma precisão, as condições e necessidades que os adultos as implicam, mesmo que tais condições - por exemplo: a pressão para crescerem depressa - não sejam benéficas ao seu desenvolvimento cognitivo e emocional, nota-se a necessidade de obter maiores dados sobre o estresse infantil e suas causas. Como os meios de comunicação, nos dias atuais, fazem parte do cotidiano de muitas famílias, principalmente das crianças, e após ler alguns estudos sobre como a televisão pode contribuir para que as crianças absorvam ainda mais o contexto de terem que se desenvolver mais rapidamente em benefício da sociedade, neste projeto em andamento, temos como objetivo ampliar o conhecimento sobre a influência da mídia, no caso, como a televisão e seus conteúdos programáticos podem ser um fator de stress nas crianças e tentar entender a relação "criança-televisão.
\end{abstract}

Palavras-chave: criança. Televisão. Estresse. Mídia. Família.

\begin{abstract}
Realizing both in practice and in studies conducted, how the child is vulnerable to environmental conditions, social and cultural rights, and ties up with some precision the conditions and needs than adults to imply, even if such conditions - for example: the pressure to grow fast - are not beneficial to their cognitive and emotional development, there is the need to obtain more data on childhood stress into their causes. Like the media, today, are part of everyday life for many families, particularly children, and after reading some studies on how television can help children to absorb more of the context of having to develop more quickly in benefit of society, this project aims to increase knowledge about the influence of media, where television and its programmatic content can be a stress factor in Brazilian children and try to understand the relation "child-television".
\end{abstract}

Keywords: children. Televisión. Stress. Media. family.

\section{Introdução}

Este artigo é parte de um projeto de pesquisa em andamento, o qual visa ampliar os conhecimentos sobre a influência da mídia, no caso, a televisão e seus conteúdos programáticos sobre a criança e se este meio de comunicação pode ser um fator de estresse nas crianças brasileiras. Por meio desta proposta, pretendo compreender a relação "criança-televisão" e como esta pode proporcionar sintomas e/ou situações de estresse em crianças de 09 a 12 anos de idade, alunos da rede pública de ensino, por meio dos conteúdos e imagens exibidas pela televisão.

Para isso, pretendo desenvolver uma análise qualitativa dos dados coletados, produzir significados sobre como o estresse infantil afeta crianças de $4^{\mathrm{a}}$ série do ensino público, e como estas reagem aos conteúdos fornecidos pela televisão. A necessidade de se desenvolver esta pesquisa se deu, ao perceber, tanto em estudos quanto em práticas realizadas, o quanto a criança está vulnerável às condições ambientais, sociais e culturais, e que esta absorve, com alguma precisão, as condições e necessidades que os adultos as implicam, mesmo que tais condições - por exemplo: a pressão para crescerem depressa - não sejam benéficas ao seu desenvolvimento cognitivo e

\begin{tabular}{|l|l|l|l|l|l|}
\hline Interfaces da Educ. & Paranaíba & v. 1 & n. 2 & p. 97-106 & 2010 \\
\hline
\end{tabular}


emocional, nota-se a necessidade de obter maiores dados sobre o estresse infantil.

Como os meios de comunicação, nos dias atuais, fazem parte do cotidiano de muitas famílias, principalmente das crianças, após ler alguns estudos sobre como a televisão pode contribuir para que as crianças absorvam ainda mais o contexto de terem que se desenvolver mais rapidamente em benefício da sociedade, pretende-se, neste projeto, analisar, qualitativamente, crianças de $4^{\mathrm{a}}$ série do ensino fundamental da rede pública e verificar como a televisão e os conteúdos exibidos em sua programação podem afetar o desenvolvimento infantil, provocando-lhes estresse.

A população alvo tem suma importância nesta pesquisa, já que as crianças de escolas públicas, provavelmente, podem pertencer a uma classe socioeconômica menos favorecida, como consequência, os pais se vêem privados perante a possibilidade de matricular seus filhos em atividades extra-escolares. Sendo assim, frente à necessidade de cumprir sua jornada de trabalho, os pais, possivelmente, deixam seus filhos em casa, e, consequentemente, essas crianças tendem a ficar suscetíveis a buscar a companhia da televisão, e, na maioria das vezes, sem o monitoramento de um adulto.

Quanto à série escolar, em que o público alvo se encontra, refere-se a crianças com idade entre 09 e 12 anos da $4^{\text {a }}$ série do ensino fundamental, levando-se em consideração que podem estar adiantadas ou serem repetentes. Essas crianças, segundo o teórico Jean Piaget, estão classificadas no período operatório concreto, onde, estruturalmente, podem conseguir trabalhar de forma adequada com a simbolização e a linguagem, apresentando, portanto, facilidade para expressar conteúdos introjetados. Sendo assim, espera-se que elas possam estar em condições de emitirem respostas que auxiliem no processo de coleta de dados, emitindo por meio da fala, gestos e expressões as possíveis consequências que a televisão possa vir a provocar no processo de desenvolvimento cognitivo e emocional dessas crianças.

Nesse contexto, esse projeto de pesquisa visa analisar qualitativamente a relação entre criança e televisão, se de alguma forma os conteúdos que são exibidos diariamente nos canais de televisão podem alterar a estrutura emocional e cognitiva da criança, a ponto de gerar ou contribuir para um estresse infantil.

No entanto, neste artigo, desenvolverei apenas uma reflexão teórica sobre o estresse de um modo geral, o estresse infantil e a mídia.

\section{Estresse: definição, causas e sintomas}

Voltando à atenção para a criança, pediatras, psicólogos, sociólogos e educadores, passaram a desenvolver estudos e pesquisas para compreender a estrutura do desenvolvimento infantil no aspecto físico, social, cognitivo e emocional. Muitos desses estudos, chamaram a atenção da sociedade para o desenvolvimento infantil e, principalmente, para o ritmo ao qual a sociedade tem se desenvolvido. Numa sociedade capitalista como a nossa, as modificações passam a ser muito rápidas: mudanças tecnológicas e sociais ocorrem todo momento; onde as pessoas precisam se adaptar e se modificar rapidamente para que não haja grandes perdas com as transformações ocorridas na sociedade. Isso afeta tanto a estrutura familiar quanto, principalmente, a estrutura de desenvolvimento da criança que precisa ser ágil para acompanhar tais mudanças. Para acompanhar a velocidade com que o mundo se transforma, as crianças são, muitas vezes, pressionadas a crescerem e a se desenvolverem mais rápido do que sua própria estrutura possibilita, vivenciando, assim, uma grande pressão a qual ainda 
não está apta, podendo sofrer danos emocionais no desenvolvimento infantil: um estresse excessivo e prejudicial.

O termo estresse, no século XVII, era utilizado na literatura inglesa de forma esporádica, seu significado era aflição e adversidade (LAZARUS e LAZARUS, apud LIPP, 2003). Posteriormente, a palavra estresse passa a representar o complexo fenômeno composto de tensão-angústia-desconforto, a qual é usada hoje pela sociedade. No século seguinte, a expressão passou a significar uma ação de força, pressão ou influência muito forte sobre a pessoa, este significado foi retirado da engenharia, em que estresse significa o "peso que uma ponte suporta até que ela se parta." (LIPP, 2003).

No século XIX, estudos começaram a ser desenvolvidos sobre uma possível relação entre os eventos emocionais relevantes e doenças físicas e mentais, mas esta noção não recebeu maior importância científica. Já no século XX, Sir Osler (apud LIPP, 2003), médico inglês procurou igualar o termo "stress" (eventos estressantes) com o excesso de trabalho e o termo "strain" (reação do organismo ao estresse) com "preocupação", oportunidade em que ele associou, juntamente, com pesquisa realizada por outros médicos, que o excesso de trabalho e de preocupação estivesse ligado a doenças coronarianas, porém seus estudos também não receberam maior atenção, até que o médico Hans Selye utilizou a palavra estresse, para determinar uma Síndrome de adaptação Geral, em que o indivíduo sofre uma grande pressão e é submetido a uma importante adaptação do organismo para enfrentá-la. Como se o ser humano fosse uma ponte, em que o excesso de peso, sobrecarga de responsabilidades podem causar danos profundos na estrutura psicofisiológica do indivíduo.

De acordo com Lipp e Malagris (2001), o estresse é um processo que se desenvolve por etapas, sendo assim, possível se ter um estresse temporário, com baixa ou grande intensidade. Todas as pessoas estão propensas ao estresse, pois tanto situações de irritação, medo, excitação, confusão e felicidade, geram o estresse. Porém não é somente o tipo de estressor que determina se o indivíduo vai ou não desenvolver o estresse. Lazzarus e Folkman (apud LIPP, 2003) apontam que as atividades cognitivas usadas pelo indivíduo para interpretar eventos ambientais são fundamentais no processo do estresse.

O stress é um processo e não uma reação única, pois no momento em que a pessoa é sujeita a uma fonte de tensão, um longo processo bioquímico se instala. Inicialmente, conforme mencionado por Selye (1984) ocorre uma mobilização hormonal, visando fortalecer o organismo a fim de capacitá-lo para a ação necessária no momento. Posteriormente, em razão da inabilidade de se manter a quebra da homeostase que ocorre nesta mobilização hormonal, o organismo que consegue sobreviver vem a se adaptar, ele aprende a resistir à tensão na qual se encontra. (LIPP, 2003, p.18).

Existem dois tipos de estressores: estressores internos e externos. As situações que enfrentamos no cotidiano e as pessoas com as quais convivemos dia-a-dia podem se configurar em agentes estressores externos. Já os estressores internos se caracterizam pelas características interpessoais, os valores morais e éticos, crenças e formas de interpretação das situações que cada indivíduo faz de sua própria vida.

De acordo com Selye (apud Lipp e Novaes, 1996), a síndrome do estresse se divide em três fases: Alerta, Resistência e Exaustão; cujos sintomas, provavelmente, todos os seres humanos já devem ter experimentado pelo menos em parte. 
A primeira fase, o Alerta, o organismo se prepara para a reação de luta ou fuga, que é essencial para a preservação da vida. $\mathrm{O}$ indivíduo entra em contato com sua fonte de estresse ou estressor, e passa a apresentar algumas reações típicas, tais como: sudorese excessiva, taquicardia, respiração ofegante, boca seca, entre outras. Nessa fase, o organismo perde seu equilíbrio interno e se prepara para enfrentar a situação a qual necessita se adaptar.

A segunda fase, a Resistência, ocorre quando o organismo tenta se recuperar do desequilíbrio sofrido na fase anterior, os sintomas são opostos ao da primeira fase e muitos sintomas desaparecem dando lugar a uma sensação de desgaste físico e cansaço, pois na fase Alerta o organismo gasta muita energia. Se, no entanto, a pessoa não consegue equilibrar suas forças internas, nesta fase de Resistência, então, o processo de estresse pode avançar a terceira fase. A fase de Exaustão é a mais perigosa, alguns sintomas da primeira fase podem retornar só que de forma mais agravante, havendo um maior comprometimento físico em forma de doenças.

$\mathrm{Na}$ teoria de Selye (1956), esse seria o modelo trifásico do estresse, porém, depois de quase cinco décadas, LIPP (2000) identifica uma quarta fase no decorrer da padronização do inventário de síndrome de estresse para adultos. Essa quarta fase, Lipp nomeou como Fase de Quase Exaustão, pois se encontra entre a fase de Resistência e a Exaustão, oportunidade em que:

[...] as defesas do organismo começam a ceder e ele já não consegue resistir às tensões e restabelecer a homeostase interior. Há momentos em que ele consegue resistir e se sente razoavelmente bem e outros em que ele não consegue mais. É comum nesta fase a pessoa sentir que oscila entre momentos de bem-estar e tranqüilidade e momentos de desconforto, cansaço e ansiedade. Algumas doenças começam a surgir demonstrando que a resistência já não é tão eficaz. (LIPP, 2003, p. 19).

O estresse excessivo é capaz de produzir inúmeras consequências para o indivíduo em si e para as pessoas e situações a sua volta, tais como, sua família, seu trabalho, empresa e comunidade onde vive. Segundo LIPP (2003), no âmbito psicológico e emocional, o estresse excessivo pode produzir cansaço mental, dificuldade de concentração, perda de memória imediata, apatia e indiferença emocional. A produtividade do indivíduo "estressado" sofre quedas frequentes e sua criatividade fica prejudicada. Devido à percepção do baixo desempenho, começam a surgir dúvidas sobre si mesmo. Há crises de ansiedade e humor depressivo. A libido fica relativamente reduzida e doenças físicas começam a aparecer. Devido a todos esses fatores, a qualidade de vida do sujeito "estressado" sofre um dano, na qual sente vontade de fugir de tudo.

\section{A Criança e o Estresse}

Os sintomas ou conseqüências do estresse podem se desenvolver tanto em adultos quanto em crianças e adolescentes. Segundo David Elkind (2004), a criança hoje é vítima de um estresse avassalador, nascido de uma mudança social rápida e desconcertante, em que as expectativas sobre ela aumentam cada vez mais. JeanJacques Rousseau (apud ELKIND, 2004), filósofo francês, estruturou o conceito moderno da infância, em que o valor da transmissão de uma herança sócio-cultural era

\begin{tabular}{|l|l|l|l|l|l|}
\hline Interfaces da Educ. & Paranaíba & v. 1 & n. 2 & p. 97-106 & 2010 \\
\hline
\end{tabular}


benéfico para a criança, porém o processo de aprendizagem deve levar em conta a percepção da criança e o seu estágio de desenvolvimento, pois a infância tem sua própria maneira de pensar, ver e sentir, diferentemente do adulto.

Devido às mudanças bruscas na sociedade, as crianças passaram a ser pressionadas a crescerem depressa, sobretudo, no âmbito intelectual. Elkind (2004) aponta que

Várias décadas atrás, a precocidade era encarada com grande desconfiança. A criança prodígio - assim se pensava - transformavase em um adulto neurótico; daí a expressão "amadurecimento precoce, deterioração precoce!". Tentar acelerar a aquisição de habilidades acadêmicas das crianças era visto como evidência de mau desempenho dos pais. (2004, p. 32).

A pressão por uma aquisição acadêmica precoce é apenas uma de muitas pressões exercidas sobre a criança, para que elas cresçam depressa. $\mathrm{O}$ vestuário, nos séculos XIX e XX, dava uma visão de um adulto em miniatura. Pensava-se que, se as crianças se vestissem como adultos, teriam maior probabilidade de se comportar como adultos. Segundo a perspectiva de Áries (1981), no século XXI, a condição do vestuário ainda permaneceu, crianças usando os mesmos modelos de roupas que os adultos, calças jeans, apertadas, sapatos de salto e maquiagens (no caso das meninas), as crianças se vestem e se movem como adultos. Elkind (2004) aponta outros exemplos de pressão social para que as crianças cresçam mais rapidamente, como: viajar sozinhas de ônibus ou avião para visitar uns dos pais (quando pai e mãe são divorciados ou não moram juntos). Em algumas situações, crianças são pressionadas a processar seus pais, por abandono; os meios de comunicação, músicas, filmes, livros e televisão, mostram conteúdos aos quais muitas crianças ainda não estão preparadas para ter acesso e podem acabar pressionando o desenvolvimento infantil.

Psicólogos e psiquiatras reconhecem que essas pressões afetam o desenvolvimento emocional da criança. Sentimentos e emoções têm seu próprio momento e ritmo de desenvolvimento, por isso não poderiam ser apressados. Crianças podem crescer depressa de algumas maneiras, como por exemplo, fisicamente, mas crescer de forma apressada emocionalmente pode ser complicado e difícil, pois o comportamento e a aparência falam "adulto", mas seus sentimentos choram "criança". A pressão para crescer depressa pode contribuir para um desenvolvimento do estresse infantil.

\section{Estágios do Desenvolvimento Infantil: operações concretas}

O psicólogo suíço Jean Piaget descreveu quatro importantes estágios no desenvolvimento do pensamento das crianças. Piaget (2003) aponta que, em cada estágio, as crianças não copiam o que encontram, mas constroem ativamente a realidade a partir de suas experiências com o ambiente. Esses quatro estágios são: período sensório-motor ( 0 a 02 anos de idade), período pré-operacional (02 a 06 anos), período operacional concreto (06 aos 12 anos) e período operacional formal (12 anos em diante). É importante ressaltar que a faixa etária de cada estágio não é precisa, pois os indivíduos podem se desenvolver ou mudar de etapas do desenvolvimento mais rápido ou mais lentamente do que outros. Essas são as diferenças individuais.

\begin{tabular}{|l|l|l|l|l|l|}
\hline Interfaces da Educ. & Paranaíba & v. 1 & n. 2 & p. 97-106 & 2010 \\
\hline
\end{tabular}


Voltando a atenção especificamente para o período operacional concreto, possível etapa do desenvolvimento que as crianças, sujeitos desse estudo, estarão inseridas, observa-se as seguintes características do desenvolvimento cognitivo, emocional e sociocultural: 1) quando as crianças atingem as operações concretas, são capazes de classificar de uma forma hierárquica objetos, animais e pessoas; 2) conseguem manipular símbolos relativos aos objetos da mesma forma como sabem manipular os próprios objetos; 3) a manipulação dos símbolos é mental, a criança consegue visualizar a atuar mentalmente um objeto, sem precisar estar com ele nas mãos ou mesmo vendo-o; 4) essa manipulação simbólica amplia muito a extensão e a variedade das explorações que a criança pode realizar.

Os níveis de competência são frequentemente ignorados quando a criança é pressionada. Segundo Elkind (2004), aprender a manipular mentalmente símbolos de maneira eficiente requer tempo, é algo que não pode ser apressado, principalmente, se a sociedade deseja que as crianças se tornem realmente competentes.

As operações concretas possibilitam novas aquisições interpessoais e intelectuais. Nesse estágio, a criança já começa a operar com regras. Essas regras podem ser tanto de leitura, aritmética, como regras sócias. A criança não realiza esse processo de forma consciente. Esse processo, Piaget (2003) denomina de "inconsciente intelectivo", ou seja, parte do pensamento da criança é inconsciente, e ela só terá consciência dos seus resultados. Possivelmente, seria por esse motivo que os adultos têm dificuldade para aceitar os problemas que as crianças possuem em lidar com regras.

Será por meio da aquisição de regras, principalmente, em jogos e na aceitação das regras impostas por outras crianças, que elas se tornam mais sociáveis, e passam a interagir com outras crianças de igual para igual. Seria nesse momento, que ocorre a primeira separação parcial dos pais e o início de novas ligações com outros adultos e crianças. O pensamento das crianças pequenas, por verem seus pais como onisciente, como deuses, passam a ser substituído por uma capacidade mental de raciocinar e chegar símbolos em contraposição com a experiência, elas começam a distinguir entre a fantasia e a realidade.

È mediante a descoberta de que os adultos não são perfeitos, que as crianças passam a eleger outros adultos para este status, tais como atletas, astros de televisão, cinema e música. Outra consequência dessa destronização dos pais é um fenômeno que Elkind (2004) denomina de "imaginação cognitiva", quando a criança percebe que seus pais desconhecem alguns assuntos ou não sabem responder a algumas perguntas, imaginam que aquele ser que sabia tudo, já não sabe nada.

A "imaginação cognitiva" seria, portanto, na idade escolar, a emancipação da criança de seus pais. Embora seja um fenômeno normal, que proporciona diversão à criança, pode ter consequências mais sérias. Pressionar as crianças a tomarem decisões que são mais adequadas aos adultos favorece a "imaginação cognitiva", podendo causar nas crianças um sentimento de autonomia, uma independência imatura, um sentimento de inferioridade e prejudicar os relacionamentos interpessoais. Fazer com que a criança pule ou passe muito rapidamente de uma fase de desenvolvimento para outra, sem respeitar suas limitações físicas, cognitivas e emocionais, seria querer que a criança crescesse mais rápido do que ela pode, e isso pode ser um grande gerador de estresse. 


\section{Causas e contribuintes do estresse infantil}

Segundo Lipp e Novaes (1996), há uma tendência em acreditar que criança não tem estresse, como se o seu organismo funcionasse de modo diferente a de um adulto. Esse pensamento, muitas vezes, é proveniente dos pais. Estes parecem pensar que seus filhos estão protegidos por algo ou um ser "superior", que os torna isentos de maiores danos na vida, mas que os pais e muitos adultos, até mesmo os profissionais da saúde desconhecem, pois a criança está sujeita às mesmas dificuldades que o adulto enfrenta. Por isso, "a criança precisa aprender a lidar com as tensões e se tornar apta para lutar ou fugir de situações que representem ameaça ao seu bem estar." (LIPP e NOVAES, 1996, p. 54).

As mudanças que ocorrem na vida da pessoa exigem o uso de energia para sua adaptação ou para superá-las. Toda mudança produz um desgaste no organismo (estresse), dessa forma, a cada fase do desenvolvimento do ser humano, este defronta com novas situações que exigem um esforço adaptativo e algumas delas são conflitantes. No caso da criança e do adolescente, essas mudanças ocorrem mais rapidamente do que no adulto, tornando-se, assim, um período suscetível ao estresse. (FRANCA e LEAL apud LIPP, 2003).

Segundo Lipp (1998), o estresse infantil se assemelha ao dos adultos em diversos aspectos. A rápida modernização, a globalização e a tecnologia cada vez mais presente no cotidiano das pessoas acarretam mudanças e adaptações igualmente a todas as idades. Toda criança, inevitavelmente, enfrentará inúmeras situações de estresse, tais como doenças, hospitalização, mudança de casa, de escola, nascimento de um irmão e a necessidade de autocontrole. Durante o seu desenvolvimento intelectual, emocional e afetivo, a criança se confronta com níveis muito alto de tensão, às vezes, superando sua capacidade ainda imatura para lidar com situações conflitantes.

Em pesquisa realizada por Vilela (1995) sobre sintomas e fontes de estresse em crianças de $1^{\mathrm{a}}$ a $4^{\mathrm{a}}$ série de escolas particulares e públicas, verificou que $60 \%$ e $65 \%$ das crianças possuem sintomas de estresse. Tal resultado demonstra que o estresse aparece na infância independente da classe social que estão inseridas.

Outra pesquisa realizada por Tricoli (apud LIPP, 2003), com crianças brasileiras, com faixa etária entre 06 a 11 anos, nas quais foi verificado um considerável nível de estresse, constatou que as meninas parecem estar mais propensas ao estresse que os meninos.

Levando em consideração alguns fatores que podem contribuir para o estresse infantil, observa-se que os meios de comunicação estão inseridos como participativos. O autor David Elkind (2004) realizou diversas pesquisas com crianças norteamericanas, sobre a atuação da mídia como fator estressante para a criança. Ele aponta que os meios de comunicação (televisão, rádio, jornais, revistas e cinema) ampliam os sentidos do espectador.

\section{A Televisão e o Estresse Infantil}

Voltando a atenção especificamente para a televisão, esta é ímpar em proporcionar acesso imediato a todas as partes do mundo. Nenhum outro meio de comunicação consegue os mesmos resultados que a televisão consegue. (ELKIND, 2004).

Esse mesmo autor comenta ainda que a televisão envolva os sentidos das pessoas imediatamente e nem sempre se faz necessário uma mediação verbal de um

\begin{tabular}{|l|l|l|l|l|l|}
\hline Interfaces da Educ. & Paranaíba & v. 1 & n. 2 & p. 97-106 & 2010 \\
\hline
\end{tabular}


narrador, para que a mensagem seja compreendida. As crianças pequenas não precisam entender a descrição verbal das imagens mostradas na televisão (guerras, tragédias, assassinatos, sexo, traição etc), as imagens falam por si só. Então, como a televisão não precisa de uma codificação ou uma decodificação verbal para ampliar a experiência das pessoas, ela fica muito acessível às crianças pequenas e, às vezes, pode apressar o seu contato com eventos não indicados por essa faixa etária.

Por isso, com a televisão, as crianças não precisam mais ser capazes de ler ou traduzir as palavras de um narrador para observar os eventos que estão acontecendo em locais distantes. [...] Com a televisão, as crianças têm acesso às notícias, às representações dramáticas e ao entretenimento, sem ter que traduzir as palavras em imagens. As imagens já estão ali. (ELKIND, 2004 p. 106).

Outro fator importante que o autor verificou em seus estudos sobre o estresse infantil e sua ligação com a televisão, é que os pais podem acabar perdendo o controle e a restrição sobre as informações que querem ou não que seus filhos tenham acesso. Mesmo que já existam videocassetes, televisão a cabo e DVD, que ajudam no controle da programação, muitos pais já não conseguem exercer controle sobre o que os filhos assistem na televisão.

Além de a televisão tornar as informações mais acessíveis às crianças e de reduzir o controle dos pais, ela também serve para homogeneizar as diferenças de classe social. A homogeneização muitas vezes ultrapassa limites sociais, étnicos, geográfico, e limites de idade. Obviamente os programas de televisão não são rigidamente graduados por idades, assim como há programação destinada a crianças, há programas para adultos e adolescentes. No entanto, o que ocorre, na maioria das vezes, é que as crianças assistem programas destinados à audiência mais velha (novelas, seriados, filmes, jornais), programas que abordam conteúdos como atividade sexual, drogas, distúrbios emocionais, assassinatos. Dessa forma, as crianças são iniciadas em questões e problemas inadequados à sua idade.

Jeffrey Cowan (1980, apud ELKIND, 2004) menciona que as razões para a homogeneização são principalmente econômicas:

De certa forma, a uniformidade e o caráter explorador da televisão aos quais muitos telespectadores fazem uma objeção de legítima - é uma função de estrutura econômica curiosa da indústria. Ao contrário de outros meios de comunicação, como livros e jornais - que obtêm sua renda dos consumidores e também dos anunciantes -, a televisão conta apenas com os anunciantes para sua renda. "[...] a grande maioria das campanhas quer atingir uma audiência urbana de 18 a 40 anos de idade, há poucos incentivos para desenvolver programas que apelem fundamentalmente a pessoas com mais de 40 anos, jovens com menos de 18 anos ou pessoas que vivem nas áreas rurais." (p. 109).

A televisão proporciona às crianças experiências de informações que possivelmente jamais poderiam ter sem ela, porém a exposição sob a televisão e seus conteúdos é uma coisa, o entendimento dessas informações, outra. Dessa forma, tornar esses conteúdos mais acessíveis às crianças não as torna nem um pouco menos confusas

\begin{tabular}{|l|l|l|l|l|l|}
\hline Interfaces da Educ. & Paranaíba & v. 1 & n. 2 & p. 97-106 & 2010 \\
\hline
\end{tabular}


ou menos perturbadoras.

Segundo Elkind (2004), uma das consequências da homogeneização dos vaivéns de uma década para outra, entre a fantasia e a realidade é criar uma pseudo-sofisticação, ou seja, fazer com que atualmente as crianças, em idade escolar, saibam muito mais do que entendem. Essa pseudo-sofisticação é o efeito da pressão da televisão sobre as crianças, encoraja pais e adultos a pressioná-las mais ainda. Entretanto, deve-se lembrar que mesmo as crianças falando, se comportando e se parecendo com adultos, ainda sentem e pensam como crianças.

Nessa perspectiva, a televisão funciona também como uma maneira de descobrir quem e o que as pessoas são. (ELKIND, 2004). Quando estas se identificam com um personagem, passam a descobrir mais coisas sobre si mesmas, ou então, as pessoas tentam se parecer cada vez mais com o personagem identificado. A maneira como as crianças são retratadas na televisão, reflete a maneira como a sociedade vê e percebe as crianças, por isso proporcionam imagens com as quais irão se identificar e procurar imitar.

Weinberg (1970) descreve bem como a televisão descreve as crianças:

As crianças (da televisão) são muito bem-comportadas e têm um bom-senso que está além a sua idade. Todas as crianças têm insights excepcionais. Em muitos programas, os insights das crianças podem ser surpreendemente filosóficos. A lição parece ser: "Ouça com atenção as crianças pequenas e você vai aprender grandes verdades. (WEINBERG, apud ELKIND, 2004 p. 113).

A televisão proporciona às crianças modelos de precocidade emocional e intelectual, constituindo, assim, uma espécie de pressão para crescerem depressa. Ao se comportarem de maneira sensata e madura, os adultos criam e aumentam as expectativas de que as crianças se tornem rapidamente mais sensatas, sábias e mais inteligentes do que elas podem ser naquele momento.

\section{Considerações Prévias}

Tendo em vista que o projeto ainda não foi concluído, e as analises não foram realizadas, pode-se apenas considerar embasado nas leituras bibliográficas dos autores e pesquisadores dessa temática, que a televisão, assim como outros meios de comunicação em massa possuem uma influência no comportamento do indivíduo, já que este está exposto a imagens e conteúdos o qual pode não estar preparado para receber, naquele momento, e esses conteúdos afetam o comportamento do homem, isso se nota em seu modo de vestir, de falar e de agir perante a sociedade. Percebe-se que aqueles indivíduos que não aderem à reprodução das imagens que a TV lhes impõe, pode não se enquadrar aos grupos sociais que seguem o modismo da televisão, ainda mais as crianças que algumas vezes têm dificuldades em diferenciar fantasia da realidade, e podem acabar misturando o conteúdo da TV com suas vidas particulares.

Afirmar que a televisão causa estresse infantil, seria impróprio porque o trabalho não foi concluído, porém percebe-se que existe sim uma grande influência, peso e importância na vida das pessoas principalmente das crianças, e que os conteúdos programáticos podem ser fortes e inadequados para determinadas idades, pois podem não compreender o real significado, mas acabam reproduzindo aquilo que vêem.

\begin{tabular}{|l|l|l|l|l|l|}
\hline Interfaces da Educ. & Paranaíba & v. 1 & n. 2 & p. 97-106 & 2010 \\
\hline
\end{tabular}


Verifica-se que a falta de controle sobre o conteúdo exibido pela televisão, assim como a dificuldade em privar as crianças de assistirem conteúdos não designados a sua faixa etária, seria o principal fator que mais prejudicaria as crianças por receberem somente informações destinadas a elas. Outro fator importante é a ausência de um adulto que monitore os programas, ou que sirva de intérprete para os conteúdos mais complexos, assim as crianças tiram suas próprias conclusões, muitas vezes ilusórias e erradas, fantasiam com esses conteúdos e os trazem para a realidade e para o meio externo (sociedade) de forma banalizada, agressiva, ou numa seriedade como se aquilo que ele estivesse vendo fosse real.

Dessa forma, as conclusões prévias deste estudo se resumem no fato de que o conteúdo programático da televisão ser um contribuinte para o desenvolvimento do estresse infantil. Acredita-se que aquelas crianças que já tenham uma predisposição ao estresse, ou que já venha de outras situações de vida estressoras (família, escola, situação socioeconômica, violência, enfermidades) estas podem estar mais propensas a se envolverem mais na ilusão da mídia e absorverem com mais facilidade a tensão e a sobrecarga que as imagens dos canais de televisão fornecem e assim consequentemente influenciam no desenvolvimento cognitivo e emocional dessas crianças, causando-lhes um estresse mais significativo.

Convém ressaltar que este projeto está em andamento, cujos resultados comprobatórios só poderão ser realizados após o término da pesquisa, assim será mais fácil confirmar o que os estudos bibliográficos apontam, e que na realidade brasileira a televisão atua da mesma forma em nossas crianças.

\section{Referências Bibliográficas}

ARIES, P. História social da criança e da família. Rio de Janeiro: LTC, 1981.

ELKIND, D. Sem tempo para ser criança. A infância estressada. Porto Alegre: Artmed, 2004.

LIPP, M. E. N. Crianças estressadas, causas, sintomas e soluções. Campinas-SP: Papirus, 2000.

LIPP, M. E. N (Org.). Mecanismos Neuropsicofisiológicos do stress: teorias e aplicações clínicas. São Paulo: Casa do Psicólogo, 2003.

LIPP, M. E. N.e NOVAES, L. E. Mitos e verdades sobre o stress. São Paulo: Contexto, 1996.

PIAGET, J. Psicologia da criança. Rio de Janeiro; DIFEL, 2003.

VILELA, M.V. Sintomas e fontes de stress em uma amostra de escolares da $1^{a}$ a $4^{a}$ série. 1995. Dissertação (Mestrado em Psicologia) - Pontifícia Universidade Católica, Campinas, 1995. 